\title{
Laser Segmental Resection for Pulmonary Tumors
}

\section{Arpad Pereszlenyi}

Department of Thoracic Surgery, Vivantes Clinics Neukoelln, Berlin, Germany

Received 18 November 2012; Accepted 20 December 2012; Published 27 February 2013

Academic Editor: Kinya Furukawa

\begin{abstract}
The laser plays a significant role in the lung parenchyma sparing resection for pulmonary neoplasms. The high performance Nd: YAG laser system emitting the $1318 \mathrm{~nm}$ wavelength exclusively up to a power of $120 \mathrm{~W}$ was used, consisting of the thin flexible quartz fibres $(400 \mu \mathrm{m})$ with low water content and a four lens focusing handpiece.
\end{abstract}

The Nd:YAG $1318 \mathrm{~nm}$ wavelength laser system enables thoracic surgeons to extend indication and include a larger number of patients in the treatment of pulmonary malignancies. This parenchyma sparing technique allows a removal of significantly higher number of lung nodules in comparison to conventional techniques (stapler, clamp resection).

A description of the laser system, the technique of the laser segmental resection for primary and secondary tumors, together with an overview of our own experience is presented.

Keywords: Laser segmental resection, Lung parenchyma-sparing resection, primary and secondary pulmonary tumors.

\section{Introduction}

It is well-known that the incidence of lung malignancies increases. The increase of primary lung cancer is especially alarming. Cancer Research (2012). But the lung is also a target organ for other secondary malignancies, such as metastases of different origins. For the primary lung cancer, the therapy of choice is its radical resection (together with systematic lymphadenectomy). For pulmonary metastases, less radical resections are necessary. Both could be challenging for thoracic surgeons in case of limited lung function and in the case of multiple bilateral lung nodules - metastases. Furthermore, the newly detected lung tumor is in most cases diagnosed in elderly, active smokers with a limited lung function and significant comorbidity. Therefore, the abovementioned planned radical resection in these "limited" patients is not possible. Thoracic surgeons face apparently a dead-lock situation having to operate radically and sparing enough functional lung parenchyma at the same time.

Copyright (C) 2013 Arpad Pereszlenyi. This is an open access article distributed under the Creative Commons Attribution License unported 3.0, which permits unrestricted use, distribution, and reproduction in any medium, provided that original work is properly cited. Contact author: Arpad Pereszlenyi E-mail: arpad.pereszlenyi@vivantes.de

How to Cite this Article: Arpad Pereszlenyi, " Laser Segmental Resection for Pulmonary Tumors," Advances in Cancer Research \& Treatment, vol. 2013, Article ID 976740, 9 pages

DOI: $10.5171 / 2013.976740$ 
This paper is dedicated to this topic; the management of the lung segmental resection for pulmonary tumors by a new laser system of $120 \mathrm{~W}$ power output within its lung parenchyma-sparing manner.

\section{Patients and Methods}

Between February 2009 and August 2012, 31 patients (18 males, 13 females, mean age 69.7 yrs range 54 - 85) underwent Laser
Segmental Resection (LSR) in our Institute. The indications for LSR were: non-small cell lung carcinoma (NSCLC) in 19 and pulmonary metastases in 12 patients. Fig.1. The most detected histologic type of NSCLC was adenocarcinoma $(n=11)$, followed by squamous-cell carcinoma $(n=6)$ and largecell carcinoma $(n=2)$. The Tumor Stage is shown in Figure 2 according to the newest, revised TNM Classification from 2009. Goldstraw et al (2007).

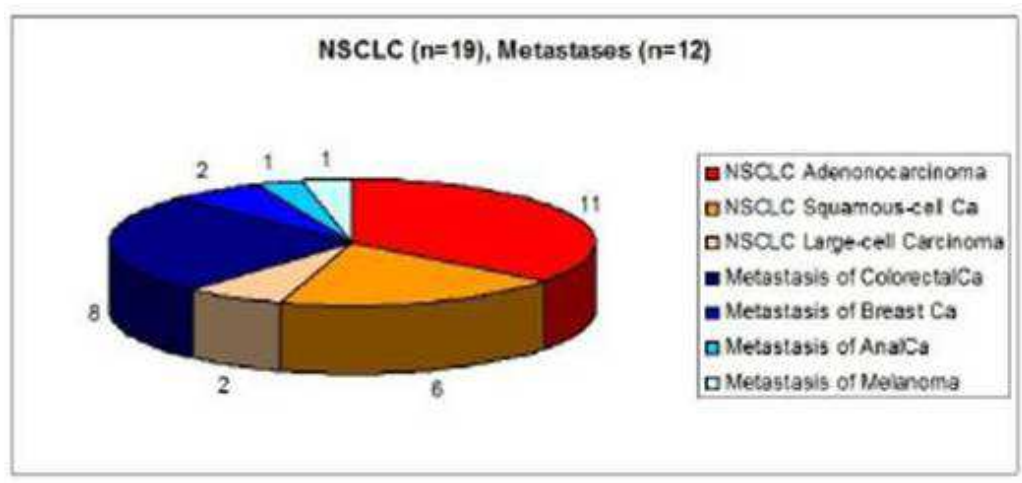

Fig. 1: Tumor Histology Distribution: $\operatorname{NSCLC~}(n=19)$, Lung Metastases $(n=12)$.

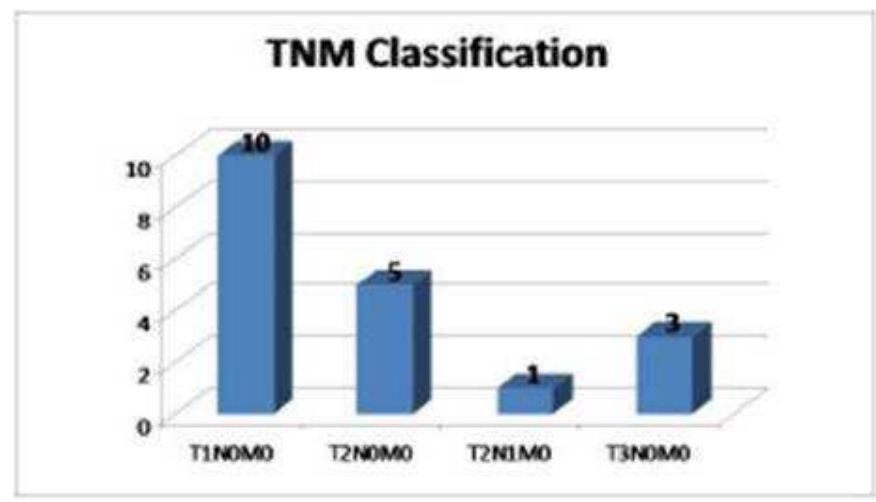

Fig. 2: Tumor Stage according to TNM Classification 2009 (n=19).

The lung metastasis of the colorectalcarcinoma $(n=8)$ was the main indication for pulmonary metastasectomy. The metastases of breast cancer $(n=2)$, melanoma and analcarcinoma (one in each) completed this indication group. Fig.1. In all of these metastases-patients $(n=12)$, the LSR was performed after fulfilling the standard criteria for pulmonary metastasectomy: primary tumors were radically removed and there were no evidence of any distant extrathoracic metastases. The systematic hilar and mediastinal lymphadenectomy was routinely added to the parenchyma-sparing segmental procedure.

All LSR were performed by the new Nd.YAG laser system of $1318 \mathrm{~nm}$ wavelength and up 
to $120 \mathrm{~W}$ power output. Fig.3. This high performance Nd: YAG laser system consisted of the thin flexible quartz fibres $(400 \mu \mathrm{m})$ with low water content and of a four lens focusing handpiece. As already stated above, this new laser system was exclusively used in all patients undergoing a lung parenchyma sparing resection in our study. The description of this new laser system is presented within the next Chapter.

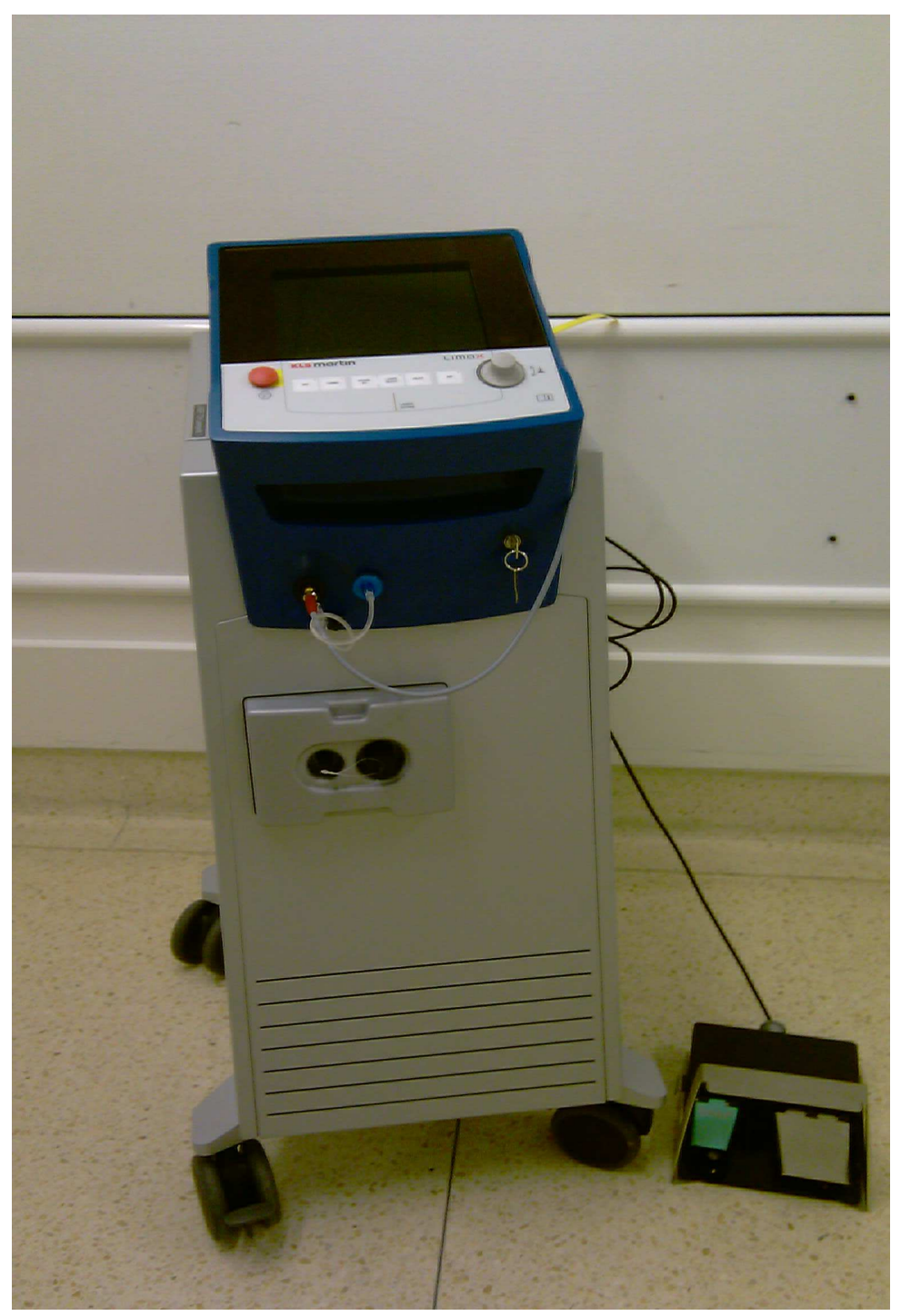

Fig. 3: Components of Modern Laser Equipment for the Application on Lung Tissue $(1318 \mathrm{~nm}$ Wavelength, up to 120 W Power Output, Beam Quality, Energy Efficiency, High Performance Smoke Evacuation System, 0.4 mm Diameter of Fibre, Focusing Handpiece, Flexible Quartz Fibres /Low Water Content/). The Picture Shows the Diode-Pumped Nd: YAG Laser Limax 120, KLS Martin Group, Tuttlingen, Germany. 
Description of New 1318 Nd: YAG Laser System of 120 Watt Power Output

Resecting the lung by any kind of photothermal application, the surgeon must be always aware of causing fistulae, leaks and bleedings from the bronchovascular pulmonary structures. Particularly when dissecting lung parenchyma, the deeper one proceeds down in central direction, the higher the risk of intraoperative bleeding and opening bronchopleural fistulas. Therefore, lung parenchyma requires a laser with a powerful coagulation capability in addition to excellent cutting properties, given the high vessel density.

Due to its parenchymal tissue containing a typical water content of $80 \%$ but a very low tissue density (just a fifth of the liver parenchyma), a very low heat capacity and a variable air content, the lung is an ideal organ for laser intervention. The absorption behavior of different lasers in water differs a lot. Bayly et al (1963); Bramson (1968); Dinstl et Fischer (1981).

The $1318 \mathrm{~nm}$ wavelength Nd:YAG laser significantly differs from the standard one (1064 nm wavelength) by its ten times higher absorption in water. The $1318 \mathrm{~nm}$ wavelength laser still offers sufficient laser light scatter, due its proximity to the beginning infrared spectrum, to satisfy the vital coagulation requirement as well. In fact the $1318 \mathrm{~nm}$ wavelength perform the intended combination effect - cutting capability plus coagulation capability - as perfectly as it could not be achieved with the $1064 \mathrm{~nm}$ wavelength. Rolle el al (1988); Rolle et al (1989). As a welcome side-effect, the strong lung tissue shrinkage provides two additional advantages: mechanical reinforcement of the coagulation effect and fistula sealing central far in the lobe region. In fact, the surfaces coagulated and sealed off through defocused irradiation with the 1318 $\mathrm{nm}$ laser withstand artificial ventilation pressures of up to $25 \mathrm{~cm} \mathrm{H} 20$.

From the above mentioned the significant technical advantage of the new laser system is more preferable compared to the other laser and/or "classic" electrocautery systems. Especially for such a precise resection as the lung segment resection, the exact anatomical resection within its anatomical boarders is required. The detailed laser segmental lung resection is being introduced within the next Chapter. To conclude this Section, the special safety requirements by using a laser system have to be mentioned. The whole personnel is informed/ trained for the use of laser. They are wearing the special goggles for eye protection during the entire procedure, and for the smoke evacuation (caused by the photothermal laser intervention) the higheffective smoke-suction system is necessary as well as the efficient room air-conditioning. A special signs marking the laser operating room, visible to for the whole personnel illuminates while the procedure lasts.

\section{Surgical Technique, Report of the Case}

Laser segmentectomy is performed via an anterolateral muscle-sparing thoracotomy after fulfilling the standard indication criteria for a lung cancer resection (histologically confirmed lung tumor in its functional and oncologic operable stage). Preoperative evaluations are the same as for a routine thoracic intervention; including a history and physical examination, chest computed tomography (CT), pulmonary function tests, and a PET scan. If there are positive mediastinal lymphatic nodes proved by the test, a video-mediastinoscopy in order to clarify the N2/N3 status is added prior to the resection.

Next, a case report presents the technique of laser segmental lung resection. A 75 year old female patient with histological confirmed Adenocarcinoma of the left lower lobe was evaluated for a lung resection. Because of the patient's significant comorbidity (ischemic heart disease, arterial hypertension, diabetes mellitus) and poor lung function (COPD, active smoker with history of 30 Pack/Years, FEV1 45\%), the limited lung resection Laser resection of the Segment 6 - was performed. 
Patient's preoperative images see in Figure 4.

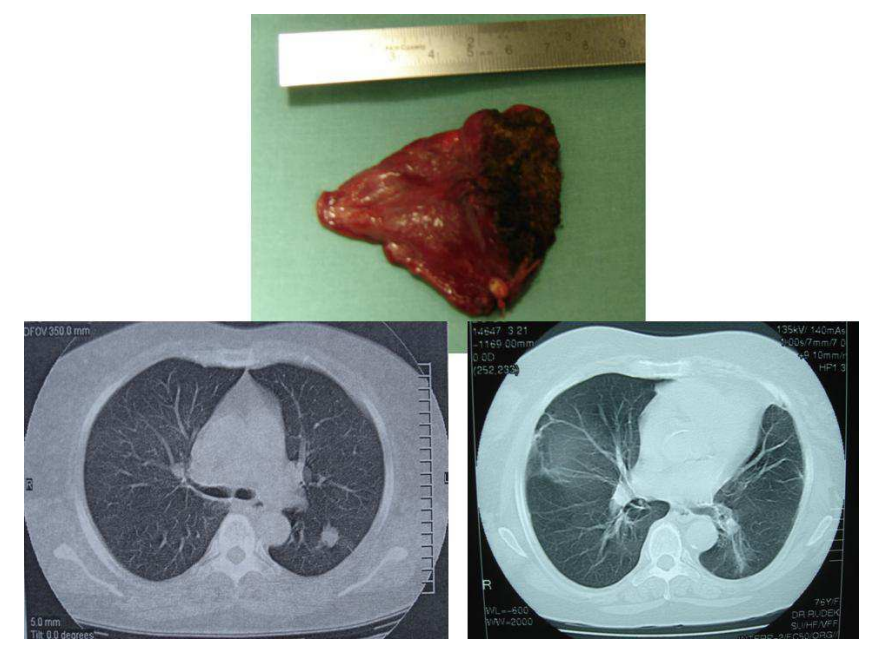

Fig. 4: Chest CT of the Case Report. The Perioperative Image is on the Left and the Postoperative Image is on the Right Side. The Resected Specimen - Segment 6 with the Tumor - can be Seen above these CT Scans.

After the mobilization of the lung hilus, the segmental vessels and bronchus were mobilized on vessel loops. Fig.5. After this step, the lung parenchyma resection was performed by the laser system within the anatomical boarders of the Segment 6. Fig.6. The visceralisation (reapproximating the visceral pleura with a running absorbable suture /4-0 Vicryl/) in order to restore the architecture of the lower lobe followed. This technique avoids a distortion of the lung tissue and allows a consistent orientation and palpation of the lung parenchyma. At the end of the procedure, the resected lung was re-insuflated by a standard way in accordance with the routine thoracic surgical practice. Radical lymphadenectomy is routinely added to this procedure.

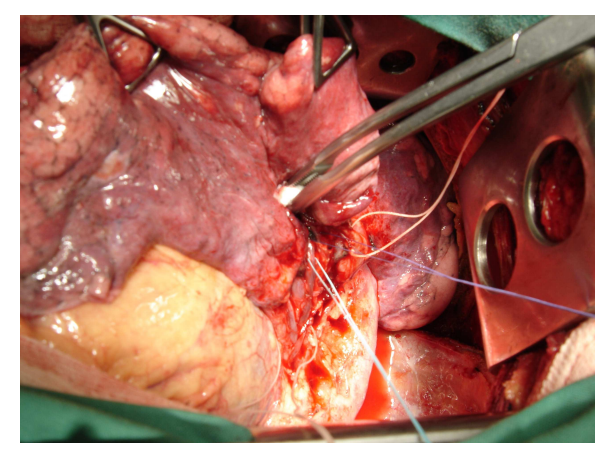

Fig. 5: Left Lower Lung Hilus Structures are Mobilized on the Vessel Loops: White Represents the Artery, Blue the Vein and Violet the Bronchus of the 6. Segment. (Dorsal View from the Left Thoracotomy Approach). 
The patient is now 2 years after the procedure, without any signs of tumor recurrence. The histological examination of the resected specimen has proved an
Adenocarcinoma of the lung $3 \mathrm{~cm}$ of diameter, radically (R0) removed via the laser resection of the Segment 6.

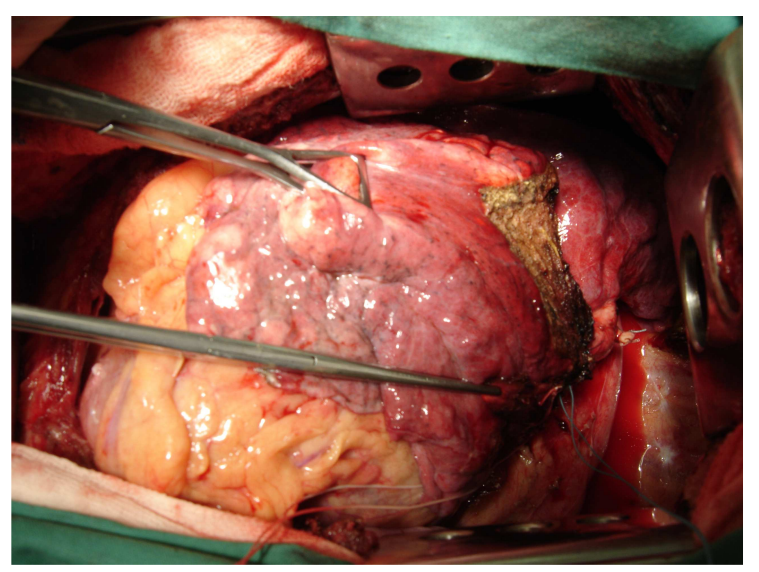

Fig. 6: Laser Segmental Resection within the Anatomical Boarders of the Segment 6.

The resected specimen as well as the patient's postoperative CT scan is shown in Figure 4.

\section{Results}

In all patients $(n=31)$ the laser segmental lung resection was performed by the above mentioned presented technique. A tumor negative bronchial (vascular) margin proven by frozen section analysis as well as by definitive histo-pathological examination was achieved in all. The distribution of resected lung segments is presented in Table 1. The TNM Stage is illustrated by Figure 2.

No intraoperative mortality was recorded. One 68 year old male patient died on 6th postoperative day due to the heart failure in accordance with his significant comorbidity (COPD, Lung Emphysema FEV1 64\% RV $250 \%$ TLC $140 \%$, ischemic heart disease with the chronic right heart insufficiency, pulmonary hypertension). The postoperative morbidity for all patients is presented in Table 2. The most common complications after the laser segmental resection were prolonged air leakage longer than 7 days in 5, as well as prolonged pleural effusion in 3 patients. The thoracoscopic decortication was necessary in one patient with pleural empyema developed on the 10th postoperative day. After this redo procedure the further postoperative course of this patient was then uneventful. In none of these patients a bronchial stump insufficiency or bronchial fistula was recorded.

Follow-up was completed for all patients with median of 15 Months, ranged from 0.2 to 39 Mo. Survival was analyzed according to Kaplan-Meier method with the estimated 1, 2, 4 years overall survival. Fig.7. 


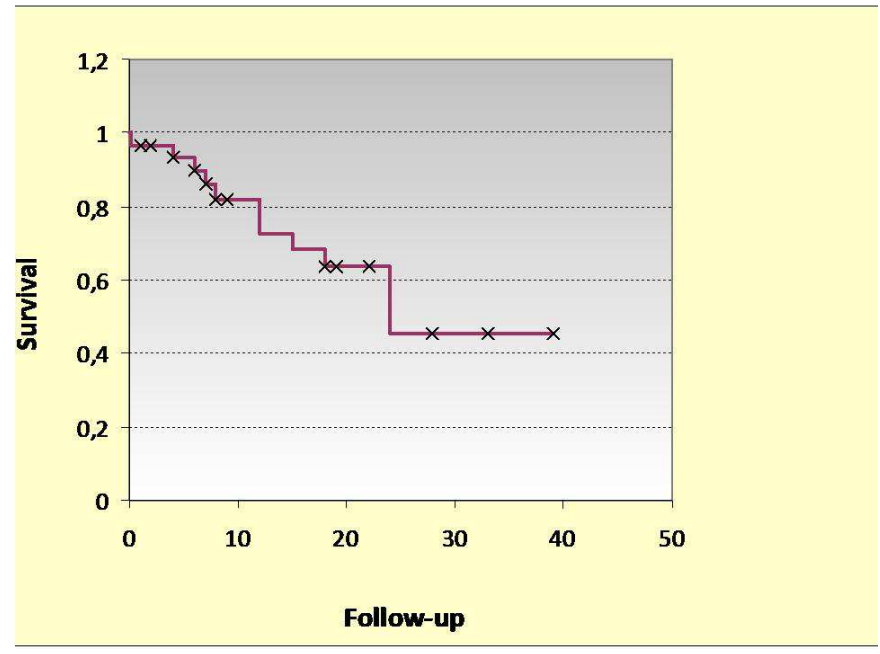

Fig. 7: Kaplan-Meier Curve Showing Survival at 20, 40, 60 Months.

\section{Discussion}

The technique of conventional lung segment resection, so called segmentectomy, is well known from the pioneer age of the thoracic surgery (pneumoftiseology) when the apical sublobar lung resections were performed for lung tuberculosis. Joseph LoCicero III (2005). Nowadays, those resections are not so widely spread due to their "not enough radicalism" for lung cancer cases. Ginsberg R.J. and Rubinstein L.V. (1995).

However, as it is already stated in the Introduction, these resections will gain more and more importance due to their lung parenchyma-sparing effect and the improving results on early postoperative morbidity and mortality. Keenan et al (2004); Harada et al (2005).

In this place, it should be emphasized that the segmental resection is also an anatomical lung resection as the lobectomy. It respects the anatomical structure of the lung with its bronchial and vascular composites together with its lymphatic flows.

A significant role in the technique of the segmental resection belongs to the laser system. Its cutting effect enables the thoracic surgeon to perform this kind of resection exactly within the anatomical boarders of the pulmonary segment. Therefore it is feasible also for segments where the "classical" segment resections can only hardly be obtained, e.g. segment 3, 9, 10 etc.

The laser lung parenchyma sparing procedure also raises the question of local tumor recurrence following this kind of thermic resection. In our recent study we could not demonstrate any case of local tumor recurrence due to the mid term follow-up (median only 15 Months). For the further investigation more long-term follow up together with more series of operated patients are needed.

However, in one of our earlier studies we could demonstrate that the tumor recurrence rate after laser segmentectomy does not significantly differ from those ones after the standard lobectomy procedures (29\% vs. $26 \%, p=0.696)$. Pereszlenyi et al (2006).

To conclude, we are convinced that radical surgical resection is still the therapy of choice in NSCLC treatment. However, laser segmental lung resection represents an optimal treatment eventuality especially for those high risk patients in whom the standard resection - lobectomy is not feasible or performable. 
Table 1: The Location of Tumors and Types of Laser Segmental Lung Resections (n=31).

\begin{tabular}{|l|l|l|l|}
\hline \multicolumn{2}{|c|}{ Right (15) } & \multicolumn{2}{c|}{ Left (16) } \\
\hline RUL & & LUL & \\
\hline S1 & 1 & S1 & 5 \\
\hline S2 & 5 & S2 & 2 \\
\hline S3 & 1 & S3 & 1 \\
\hline RML (S4) & 2 & S4 & 4 \\
\hline RLL & & LLL & \\
\hline S6 & 4 & S6 & 4 \\
\hline S8 & 1 & S8 & \\
\hline S9 & 1 & S9 & \\
\hline
\end{tabular}

Table 2: Postoperative Morbidity after Laser Segmental Resection $(n=31)$.

\begin{tabular}{|c|l|}
\hline Prolonged drainage of pleural effusion & 3 \\
\hline Prolonged drainage for air-leak & 5 \\
\hline Pneumonia & 3 \\
\hline Empyema & 1 \\
\hline Bronchofistula/ Bronchial stump Insufficiency & 0 \\
\hline Atrial fibrillation & 2 \\
\hline
\end{tabular}

\section{Acknowledgment}

The Author has no conflict of Interest.

\section{References}

Bayly, J. G., Kartha, V. B. \& Stevens, W. H. (1963). "The Absorption Spectra of Liquid Phase H2O, HDO, and D20 from 0.7 Micron to 10 Micron," Infrared Physics, 3211 - 223.

Bramson, M. A. (1968). Infrared Radiation: A Handbook for Applications, Plenum Press, New York, USA.

Cancer Research UK (2012). “The Latest Lung Cancer Mortality Statistics in UK, Europe and Worldwide," http://www.cancerresearchuk.org/ [Online],

Dinstl, K. \& Fischer, P. L. (1981). 'Der Laser. Grundlagen und Klinische Anwendung,' Springer, Berlin, Heidelberg, New York.
Ginsberg, R. J. \& Rubinstein, L. V. Lung Cancer Study Group. (1995). "Randomized Trial of Lobectomy versus Limited Resection for T1 N0 Non-Small Cell Lung Cancer," Ann Thorac Surg 60615 - 622.

Goldstraw, P., Crowley, J., Chansky, K., Giroux, D. J., Groome, P. A., Rami-Porta, R., Postmus, P. E., Rusch, V. \& Sobin, L. International Association for the Study of Lung Cancer International Staging Committee; Participating Institutions (2007). “The IASLC Lung Cancer Staging Project: Proposals for the Revision of the TNM Stage Groupings in the Forthcoming (Seventh) Edition of the TNM Classification of Malignant Tumours," J Thorac Oncol, 2 (8) 706 - 714.

Harada, H., Okada, M., Sakamoto, T., Matsuoka, H. \& Tsubota, N. (2005). "Functional Advantage after Radical Segmentectomy versus Lobectomy for Lung Cancer," Ann Thorac Surg, 80 (6) 2041- 2045. 
Keenan, R. J., Landreneau, R. J., Maley, R. H. Jr., Singh, D., Macherey, R., Bartley, S. \& Santucci, T. (2004). "Segmental Resection Spares Pulmonary Function in Patients with Stage I Lung Cancer," Ann Thorac Surg, 78 (1) 228 233.

LoCicero, J. III (2005). 'Segmentectomy and Lesser Pulmonary Resections,' IN: Shields T.W.: General Thoracic Surgery. Lippincott Williams \& Wilkins, 496-502.

Pereszlenyi, A., Rolle, A., Huscher, S., Koch, R. \& Rudek, B. (2006). 'Laser Segmental Lung Resection versus Lobectomy for Stage I NonSmall Cell Lung Cancer - A Prospective Single Institution Study,' Eur Surg, 38 (Suppl.210) 55.

Rolle, A., Thetter, O., Häussinger, K., Hallfeldt, K. K. J. \& Schmölder, A. (1989). 'Einsatz des Neodym YAG Lasers in der Thoraxchirurgie,' Herz Gefäss Thorax Chir 3 (5) 85 - 91.

Rolle, A., Unsöld, E., Ruprecht, L., Permanetter, W. \& Frank, F. (1988). 'Morphologic Aspects of Nd: YAG Laser Application (Wave Lengths $1064 \mathrm{~nm}$ and $1318 \mathrm{~nm}$ ) on Lung Tissue,' Laser Med Surg, 4 (1) 10 - 14. 